\title{
Brain Disposition of cis-para-Methyl-4-Methylaminorex (cis-4,4'-DMAR) and Its Potential Metabolites after Acute and Chronic Treatment in Rats: Correlation with Central Behavioral Effects ${ }^{[}$
}

\author{
Jacopo Lucchetti, Claudio M. Marzo, ${ }^{1}$ Alice Passoni, Angelo Di Clemente, Federico Moro, \\ Renzo Bagnati, Marco Gobbi, and Luigi Cervo \\ Departments of Molecular Biochemistry and Pharmacology (J.L., M.G.), Neuroscience (C.M.M., A.D.C., F.M., L.C.), and \\ Environmental Health Science (A.P., R.B.), IRCCS—Istituto di Ricerche Farmacologiche Mario Negri, Milan, Italy
}

Received February 16, 2017; accepted April 3, 2017

\begin{abstract}
para-Methyl-4-methylaminorex $\left(4,4^{\prime}\right.$-DMAR) is a phenethylamine derivative with psychostimulant activity whose abuse has been associated with several deaths and a wide range of adverse effects. We recently validated a high-performance liquid chromatography - tandem mass spectrometry method to measure the compound's concentrations in plasma, and we applied it to describe the pharmacokinetic properties of 4,4'-DMAR after a single dose in rats. In this study, we investigated the brain disposition and metabolism of cis-4,4'-DMAR after intraperitoneal injection as well as its central behavioral effects. Locomotor activity increased after a single injection of $10 \mathrm{mg} / \mathrm{kg}$, peaking at 2 hours and disappearing at 5 hours; in these conditions, brain absorption was very rapid, ( $t_{\max }=30-60$ minutes) and large (brain-to-plasma ratio $=24$ ); the half-life was approximately
\end{abstract}

50 minutes. After 14 daily doses, the compound's effect on locomotor activity was greater (approximately $20 \%$ compared with the effect after the first dose), but not for pharmacokinetic reasons. Using high-resolution mass spectrometry, we also identified four metabolites of cis-4,4'-DMAR in the plasma and brain of treated rats. Semiquantitative analysis indicated low brain permeability and very low brain concentrations, suggesting that these metabolites do not contribute to central behavioral effects; however, the metabolite originating from oxidation of the paramethyl group (M2) persisted in the plasma longer and at higher concentrations than the parent molecule and could be used to evaluate drug intake in human consumers. Finally, we describe the rewarding effect of cis-4,4'-DMAR in the conditioning place preference test, suggesting a high risk of addiction in humans.

\section{Introduction}

para-Methyl-4-methylaminorex (4,4'-DMAR) is a derivative of the scheduled psychostimulants 4-methylaminorex (4-MAR) (Bunker et al., 1990; Kankaanpää et al., 2001, 2002; Meririnne et al., 2004) and aminorex (Poos et al., 1963; Costa et al., 1971; Kay et al., 1971; Davis and Brewster, 1988; Hofmaier et al., 2014). 4,4'-DMAR was known as a "new psychoactive substance" until it was added to schedule II of the 1971 United Nations Convention on Psychotropic Substances (March 2016) (https://documents-dds-ny.un.org/doc/ UNDOC/GEN/V16/087/41/PDF/V1608741.pdf?OpenElement; http://www.who.int/medicines/access/controlled-substances/5.5_ 44_DMAR_CRev.pdf?ua=1; http://www.unodc.org/unodc/en/

This research was supported by the Drug Policies Department of the Presidency of the Council of Ministers of Italy [Project NPS-Risk Assessment].

${ }^{1}$ Current affiliation: Department of Diagnostics and Public Health, Verona University, Verona, Italy.

https://doi.org/10.1124/jpet.117.240788.

S This article has supplemental material available at jpet.aspetjournals.org.
press/releases/2016/March/seven-substances-scheduled-at-the59th-session-of-the-commission-on-narcotic-drugs.html). Its appearance in Europe was notified for the first time in 2012 by the Netherlands national focal point. It was originally sold primarily through illicit Internet retailers as a "research chemical" under different names (e.g., Serotoni, 4-methylU4Euh, or 4-methyl-euphoria) and mainly in powder form. More recently, 4,4'-DMAR has been sold on the "street market," camouflaged like common illicit drugs such as tablets with logos similar to "ecstasy" tablets (http://www.emcdda. europa.eu/publications/risk-assessment/44-dmar).

From the first notification and over a short period, the presence of 4,4'-DMAR has been analytically confirmed in 31 deaths reported to the European Union Early Warning System; however, the presence of other psychoactive drugs in the blood of these patients, as well as in the materials seized, suggested that 4,4'-DMAR might not be the (only) cause of death (Cosbey et al., 2014; http://www.emcdda.europa.eu/ publications/risk-assessment/44-dmar). Furthermore, a number of adverse effects, including agitation, hyperthermia,

ABBREVIATIONS: 4,4'-DMAR, para-methyl-4-methylaminorex; 4-MAR, 4-methylaminorex; ACN, acetonitrile; AUC, area under curve; BBB, blood-brain barrier; CPP, conditioning place preference; EMA, European Medicines Agency; $\mathrm{HCOOH}$, formic acid; HPLC, high-performance liquid chromatography; IS, internal standard; $\mathrm{m} / \mathrm{z}$, mass-to-charge ratio; $\mathrm{MeOH}$, methanol; MP-A, mobile phase A; MP-B, mobile phase B; MS, mass spectrometry; PK, pharmacokinetics; QC, quality control; $t_{1 / 2}$, half-life. 
convulsions, breathing problems, and cardiac arrest, were reported in parallel (Glanville et al., 2015; http://www. emcdda.europa.eu/publications/risk-assessment/44-dmar).

Nausea, dysphoria, sweating, increased heart rate, dilated pupils, jaw clenching, restless legs, amnesia, feeling lethargic or "wiped out," foaming at the mouth, dry mouth, facial spasms, psychosis, and hallucinations are also reported by users in Internet forums; these unwanted effects are similar to those of other sympathomimetic drugs such as 3,4-methylenedioxymethamphetamine and mephedrone (Glanville et al., 2015; http://www.emcdda.europa.eu/publications/risk-assessment/ 44-dmar). The doses associated with adverse effects $(5-200 \mathrm{mg}$, orally) overlap those required for the desired effects.

The molecular structure of 4,4'-DMAR involves two chiral centers within the oxazoline ring, resulting in four distinct ( \pm )-cis and ( \pm )-trans enantiomers (Brandt et al., 2014; http:// www.emcdda.europa.eu/publications/risk-assessment/44-dmar). When the reference standard was available, the cis form was confirmed in 18 deaths in the United Kingdom and in seized materials, but the presence of the trans form in the drug market cannot be excluded (Brandt et al., 2014; http://www.emcdda. europa.eu/publications/risk-assessment/44-dmar). The activity of these two isomers was recently investigated in vitro on rat brain synaptosomes; cis-4,4'-DMAR is a potent, nonselective releaser of dopamine, norepinephrine, and serotonin through interaction with the corresponding monoamine transporters, acting as a substrate at the dopamine and norepinephrine transporters $\left(\mathrm{EC}_{50}=8.6\right.$ and $26.9 \mathrm{nM}$, respectively) with potency comparable to aminorex and $d$-amphetamine. However, the potency to induce serotonin release via the serotonin transporter $\left(\mathrm{EC}_{50}=18.5 \mathrm{nM}\right)$ was higher than these two psychostimulants (Brandt et al., 2014). The trans isomer also induces dopamine and noradrenaline release $\left(\mathrm{EC}_{50}=24.4\right.$ and $31.6 \mathrm{nM}$, respectively) but it acts as an uptake blocker at the serotonin transporter (McLaughlin et al., 2015). The potency of $c i s-4,4^{\prime}$-DMAR for inducing the release of all three monoamines is reflected in its potential for serious side effects.

Information about the pharmacokinetics (PK) of 4,4'-DMAR and its metabolism in vivo is scarce. We recently validated a high-performance liquid chromatography (HPLC)-tandem mass spectrometry (MS/MS) method for quantification of cis-4,4'-DMAR in rat and human plasma and applied it for preliminary evaluation of the PK profile after a single intravenous injection in rats (Lucchetti et al., 2016). There was a rapid distribution phase lasting about 1 to 2 hours, followed by a slow elimination phase with a terminal halflife $\left(t_{1 / 2}\right)$ of about 5 hours. The bioavailability after intraperitoneal injection was about 20\% (Lucchetti et al., 2016), lower than the analog 4-methylaminorex (Meririnne et al., 2004).

Here, we focused on the PK profile of cis-4,4'-DMAR in brain tissue and, in parallel, its psychostimulant activity and ability to induce motivational properties in the conditioned place preference (CPP) test. To our knowledge, this study is also the first to investigate in vivo metabolites of the molecule in the plasma and brain.

\section{Materials and Methods}

\section{Chemicals and Reagents}

Acetonitrile (ACN), methanol (MeOH), 2-propanol, and formic acid $(\mathrm{HCOOH})$ were from Sigma-Aldrich (Milan, Italy); all solvents were of HPLC-mass spectrometry (MS) grade. HPLC-MS-grade water was obtained in house from a Milli-Q system (Millipore, Bedford, MA). The internal standard (IS), carbamazepine hydrochloride, was from Sigma-Aldrich. cis-4,4'-DMAR was purchased, on March 2014, from an Internet vendor (http://www.chems-direct.org/serotoni-4-4DMAR). The powder contained 4,4'-DMAR in the cis form with purity $>99 \%$, as previously confirmed (Lucchetti et al., 2016). On delivery, cis-4,4'-DMAR powder was stored at $4^{\circ} \mathrm{C}$ in dry conditions. Cocaine hydrochloride for behavioral studies was purchased from MacFarlan-Smith (Edinburgh, UK).

cis-4,4'-DMAR stock solutions and working solutions for standard points $(0.025,0.05,0.1,0.5,1,5$, and $10 \mu \mathrm{g} / \mathrm{ml})$ and quality controls (QCs) $(0.025,0.075,3.0$, and $7.5 \mu \mathrm{g} / \mathrm{ml})$ were prepared in $\mathrm{MeOH}$ as previously described (Lucchetti et al., 2016). A stock solution of carbamazepine was also prepared in $\mathrm{MeOH}$ at a concentration of $1 \mathrm{mg} / \mathrm{ml}$ and diluted to $5 \mu \mathrm{g} / \mathrm{ml}$ in the same organic solvent as needed. Stock and working solutions were stored at $-20^{\circ} \mathrm{C}$ until use.

\section{Animals}

Procedures involving animals were conducted at the IRCCSIstituto di Ricerche Farmacologiche Mario Negri (Milan, Italy), which adheres to the principles set forth in the following laws, regulations, and policies governing the care and use of laboratory animals: Italian Governing Law (Decreto Legislativo 26/2014; authorization no. 19/2008-A issued March 6, 2008 by the Ministry of Health), Mario Negri Institutional Regulations and Policies providing internal authorization for persons conducting animal experiments (Quality Management System Certificate UNI EN ISO 9001:2008; regulation no. 6121), the National Institutes of Health Guide for the Care and Use of Laboratory Animals (2011 edition), and European Union directives and guidelines (EEC Council Directive 2010/63/UE). The Statement of Compliance (Assurance) with the Public Health Service Policy on Human Care and Use of Laboratory Animals was recently reviewed (September 9, 2014) and will expire on September 30, 2019 (Animal Welfare Assurance no. A5023-01).

Naïve male Wistar rats (Envigo RMS Srl, San Pietro al Natisone, Udine, Italy) were used. After arrival, rats weighing 175-200 g were housed two per cage at constant room temperature $\left(21 \pm 1^{\circ} \mathrm{C}\right)$ and $60 \%$ relative humidity with a 12-hour light cycle (lights on from 7:00 AM to 7:00 PM) with food and water ad libitum (Global Diet 2018S; Envigo). Animals were allowed to adapt to laboratory conditions for at least 2 weeks and were handled daily during this period.

\section{PK Studies in Rats}

cis-4,4'-DMAR was dissolved in sterile $0.9 \%$ saline at a concentration of $5 \mathrm{mg} / \mathrm{ml}$ and was injected intraperitoneally in a volume of $2 \mathrm{ml} / \mathrm{kg}$.

Single-Dose Study. A group of rats were treated intraperitone-

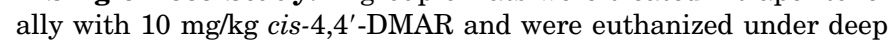
anesthesia (5\% isoflurane) at different times after injection ( $n=3$ to 4 at 15 minutes, 30 minutes, 1 hour, 2 hours, 4 hours, 6 hours, 8 hours, or 24 hours). Blood samples were transferred to heparinized tubes and kept in ice; plasma was obtained by centrifugation at $2000 \mathrm{~g}$ for 15 minutes and stored at $-20^{\circ} \mathrm{C}$ until analysis. Brain tissues were immediately removed after decapitation and kept on dry ice and were then homogenized in 10 volumes of Milli-Q and stored at $-20^{\circ} \mathrm{C}$ until analysis.

Multiple-Dose Study. Eight rats were injected intraperitoneally with $10 \mathrm{mg} / \mathrm{kg}$ cis-4,4'-DMAR once a day; four rats were euthanized 24 hours after the 13th dose and the others were euthanized 30 minutes after the 14 th dose. Blood and brain tissues were removed and processed as described above.

Plasma and brain PK profiles were analyzed using a noncompartmental model to obtain PK parameters. The peak concentration $\left(C_{\max }\right)$ and the time taken to reach it $\left(t_{\mathrm{max}}\right)$ were taken directly from the data; the $t_{1 / 2}$, the area under the curve (AUC) from 0 to the last time point $\left(\mathrm{AUC}_{0-\mathrm{t}} \mathrm{t}\right.$, and the AUC from 0 to infinity $\left(\mathrm{AUC}_{0-\text { inf }}\right)$ were obtained with PKSolver, a freely available menu-driven add-in program for 
Microsoft Excel (Microsoft Corporation, Redmond, WA) (Zhang et al., 2010).

\section{Identification of cis-4,4'-DMAR Metabolites in the Plasma and Brain}

OECD QSAR Toolbox freely available software (version 3.2, http:// www.qsartoolbox.org/it; Organization for Economic Cooperation and Development, Paris, France) was used first to predict cis-4,4'-DMAR metabolites. The predicted ones were then checked in plasma and brain samples of treated rats (pool of samples at each time point, as described above) using a high-resolution mass spectrometer (LTQ Orbitrap XL; Thermo Fisher Scientific, Indianapolis, IN) coupled to a liquid chromatography system (Agilent 1200 Series; Agilent Technologies, Santa Clara, CA). cis-4,4'-DMAR metabolites were extracted from a pool of plasma and brain samples of three to four rats at each time point by protein precipitation, as described below. HPLC separation was done with a Kinetex C18 column $(150 \times 2.1 \mathrm{~mm}, 5-\mu \mathrm{m}$ particle size) with a SecurityGuard ULTRA cartridge for the C18 precolumn (both from Phenomenex Inc., Torrance, CA), using an elution mixture composed of mobile phase A (MP-A) $(0.1 \% \mathrm{HCOOH}$ in water) and mobile phase B (MP-B) (ACN). The elution gradient was from $2 \%$ to $50 \%$ of MP-B in 20 minutes, to $99 \%$ of MP-B in 1 minute and was held at $99 \%$ for 2 minutes and re-equilibrated for 7 minutes at $2 \%$ of MP-B. The flow rate was set at $0.2 \mathrm{ml} / \mathrm{min}$ with an injection volume of $5 \mu \mathrm{l}$.

The LTQ Orbitrap XL was equipped with an Ion Max Source used in positive electrospray ionization mode (Thermo Fisher Scientific); a complete scan at 60,000 resolving power, looking for molecules within the mass-to-charge ratio $(\mathrm{m} / z)$ range of $50-1000$, was performed on extracted plasma and brain samples from cis-4,4'-DMAR-treated rats and untreated rats used as a control. Fragmentation spectra were acquired simultaneously (collision-induced dissociation, $35 \mathrm{eV}$; resolving power, 15,000) on the same samples using a targeted method that selected the calculated $\mathrm{m} / z( \pm 10 \mathrm{ppm})$ corresponding to metabolites previously predicted with the OECD QSAR Toolbox. No other peaks, corresponding to possible unpredicted metabolites, were found in the samples of treated rats.

\section{HPLC-MS/MS Quantification in the Plasma and Brain}

Plasma and brain levels of cis-4,4'-DMAR, as well as metabolites found in significant levels, were measured by HPLC-MS/MS using a triple quadrupole instrument to establish the time-course profiles in both matrices.

A recently validated method was used (Lucchetti et al., 2016). Briefly, plasma and brain samples were thawed at room temperature and processed in parallel with two replicates of QC samples at three concentrations $(7.5,300$, and $750 \mathrm{ng} / \mathrm{ml}$ for plasma or 75,3000 , and $7500 \mathrm{ng} / \mathrm{g}$ for brain) and with freshly prepared calibration curves linear in the range of $2.5-1000 \mathrm{ng} / \mathrm{ml}$ for plasma samples or $25-10,000 \mathrm{ng} / \mathrm{g}$ for brain samples. After $5 \mu \mathrm{l}$ IS working solution (final concentration of $500 \mathrm{ng} / \mathrm{ml}$ or $5000 \mathrm{ng} / \mathrm{g}$ ) was added, the solutions were mixed with $500 \mu \mathrm{l}$ cold ACN (with $1 \% \mathrm{HCOOH}$ ) to allow protein precipitation and were then centrifuged at $4^{\circ} \mathrm{C}$ for 10 minutes at $13,000 \mathrm{~g}$. The supernatants were dried under nitrogen and the residues were resuspended in $500 \mu \mathrm{l}$ water/ACN [98\%/2\% (v/v)] containing $0.1 \% \mathrm{HCOOH}$. Ten microliters was injected into an Alliance 2795 model HPLC system coupled to a Quattro Micro API triple quadrupole mass spectrometer (both from Waters Corporation, Milford, MA). The autosampler temperature was $6^{\circ} \mathrm{C}$. Separation was performed on a Kinetex C18 column $(150 \times 2.1 \mathrm{~mm}, 5$ - $\mu \mathrm{m}$ particle size $)$ at $30^{\circ} \mathrm{C}$ with a SecurityGuard ULTRA cartridge C18 precolumn (Phenomenex). The elution solvents were $0.1 \% \mathrm{HCOOH}$ in water (MP-A) and $0.1 \% \mathrm{HCOOH}$ in acetonitrile (MP-B). Elution started with $98 \%$ of MP-A and $2 \%$ MP-B for 2 minutes, followed by a 13-minute linear gradient to $100 \%$ of MP-B, which was held for 2 minutes, and a 2 -minute linear gradient to $98 \%$ of MP-A, which was maintained for 8 minutes to equilibrate the column; the flow rate was $0.200 \mathrm{ml} / \mathrm{min}$.
The total run time was 25 minutes: retention times for $c i s-4,4^{\prime}$-DMAR and IS were 10.36 and 11.92 minutes, respectively.

The mass spectrometer, operated in positive electrospray ionization multiple reaction monitoring mode, acquired the mass transitions $\mathrm{m} / \mathrm{z}$ $191.4 \rightarrow \mathrm{m} / \mathrm{z} 148.3$ (quantification ion transition; collision energy, $10 \mathrm{eV}$ ) and $\mathrm{m} / \mathrm{z} 191.4 \rightarrow \mathrm{m} / \mathrm{z} 131.3$ (qualitative ion transition; collision energy, $22 \mathrm{eV}$ ) for cis-4,4'-DMAR; ion transitions $\mathrm{m} / \mathrm{z} 237.3 \rightarrow \mathrm{m} / \mathrm{z}$ 194.2 (quantification ion transition; collision energy, $17 \mathrm{eV}$ ) and $\mathrm{m} / \mathrm{z}$ $237.3 \rightarrow \mathrm{m} / \mathrm{z} 165.2$ (qualitative ion transition; collision energy, $40 \mathrm{eV}$ ) were used for the IS. Capillary and cone voltage were set at $3.5 \mathrm{kV}$ and $15 \mathrm{~V}$, respectively. The HPLC-MS/MS system was controlled by MassLynx software (version 4.1; Waters Corporation).

To accept the analytical run, QCs and back-calculated calibrators had to satisfy criteria indicated in the European Medicines Agency (EMA) guidelines on bioanalytical method validation (http://www. ema.europa.eu/docs/en_GB/document_library/Scientific_guideline/2011/ 08/WC500109686.pdf). Raw HPLC-MS/MS analysis data were processed with GraphPad Prism software (GraphPad Software Inc., La Jolla, CA) to plot the calibration curve and quantify cis-4,4'-DMAR levels in the plasma and brain. Since the method for cis-4,4'-DMAR quantification was validated previously in plasma, performance of the method was further examined in the brain homogenate following EMA guidelines (http://www.ema.europa.eu/docs/en_GB/document_library/ Scientific_guideline/2011/08/WC500109686.pdf) (validation results are reported in Supplemental Fig. 1 and Supplemental Tables 1-5). All calibration curves analyzed during method validation showed slopes highly reproducible with determination coefficients $\left(r^{2}\right)$ always over 0.99 ; the accuracy of the back-calculated concentrations was always within the acceptance limits. The lower limit of quantification was set at $25 \mathrm{ng} / \mathrm{g}$, and the selectivity of the methods was confirmed in six different matrices. The mean accuracy calculated on six replicates of QCs at four concentrations $(25,75,3000$, and $7500 \mathrm{ng} / \mathrm{g})$ was in the range of $93.9 \%-108.0 \%$ (intraday, in the same analytical run) and $100.7 \%-105.1 \%$ (interday, over 3 different days); precision, expressed as the percent coefficient of variation, was $3.1 \%-11.2 \%$ (intraday) and $1.9 \%-11.4 \%$ (interday). Recoveries of cis-4,4'-DMAR (75, 3000, and $7500 \mathrm{ng} / \mathrm{g})$ and IS $(5000 \mathrm{ng} / \mathrm{g})$ were within the ranges of $95.3 \%-$ $100.7 \%$ and $87.8 \%-92.4 \%$, respectively; ion suppression/enhancement (expressed as the matrix factor) of the assay was calculated for cis-4,4' $\operatorname{DMAR}(75,3000$, and $7500 \mathrm{ng} / \mathrm{g})$ and IS $(5000 \mathrm{ng} / \mathrm{g})$ in six different lots of brain homogenate. The IS-normalized matrix factor was consistent across the concentrations, and the overall percent coefficient of variation ranged from $4.3 \%$ to $6.3 \%$. We also confirmed the stability of cis-4,4'-DMAR (25 and $7500 \mathrm{ng} / \mathrm{g}$, six replicates) in brain homogenate under four conditions: bench-top stability ( 2 hours at room temperature), long-term storage stability $\left(2\right.$ weeks at $\left.-20^{\circ} \mathrm{C}\right)$, stability after two freeze-thaw cycles, and autosampler stability (48 hours at $6^{\circ} \mathrm{C}$ ). All validation data are consistent with the requirements indicated in the EMA guidelines and are comparable to those obtained in plasma (Lucchetti et al., 2016).

\section{Behavioral Studies}

cis-4,4'-DMAR was dissolved in sterile $0.9 \%$ saline at $0.5-5 \mathrm{mg} / \mathrm{ml}$ and was injected in a volume of $2 \mathrm{ml} / \mathrm{kg}$ to achieve doses of 1,3 , and $10 \mathrm{mg} / \mathrm{kg}$. Cocaine hydrochloride was dissolved in sterile $0.9 \%$ saline at $5 \mathrm{mg} / \mathrm{ml}$ and injected in a volume of $2 \mathrm{ml} / \mathrm{kg}$ to achieve the dose of $10 \mathrm{mg} / \mathrm{kg}$.

\section{Locomotor Activity}

We tested the ability of cis-4,4'-DMAR to influence spontaneous motor activity during the light phase of the day (between $10 \mathrm{AM}$ and 4 PM), according to published data (Dolezal and Krsiak, 2002), with some modifications. Rats were kept in individual transparent cages $(42 \times 28 \times 21 \mathrm{~cm}$, length $\times$ width $\times$ height) with sawdust bedding. Each cage was placed between metal frames $(54 \times 50 \times 37 \mathrm{~cm})$ holding two sets of parallel photo beams, crossing the cage $3 \mathrm{~cm}$ above the floor (Multiple Activity Cage, catalog number 47420; Ugo Basile, Comerio, 
Varese, Italy). The device counts the number of movements by recording the number of infrared beam interruptions. On the testing day (after 1 hour of acclimation), rats were randomly allocated to the transparent cage and baseline motor activity counts were first automatically recorded in 10-minute time bins for 1 hour using dedicated software (Ugo Basile). Afterward, the rats were injected intraperitoneally with vehicle or 3 and $10 \mathrm{mg} / \mathrm{kg} 4,4^{\prime}$-DMAR, and their locomotor activity was recorded as the number of beam breaks in a 10-minute time bin over a period of 5 hours.

Spontaneous locomotor activity was measured after the first and 14th doses of a 14-day chronic treatment and after a subsequent 48-hour washout period.

\section{CPP}

Apparatus. Rats were conditioned and tested in standard place preference boxes (TSE Systems GmbH, Bad Homburg, Germany) consisting of three compartments. The two outer conditioning compartments $(30 \times 25 \times 30 \mathrm{~cm})$ were visually (black/white stripes versus gray) and structurally (grid floor versus smooth floor) different and separated by a smaller white middle compartment $(10 \times 25 \times 30 \mathrm{~cm}$, length $\times$ width $\times$ height) used to introduce the animal to the apparatus during the pretest and test sessions. During the pretest and test sessions, arched gateways provided access to the two adjacent conditioning compartments, which allowed the animals to move freely around the entire apparatus. During conditioning sessions, the rats were placed in one of the two conditioning compartments and access to the other compartments was blocked by inserting dividers without a gateway between the compartments. All compartments were equipped with photosensors to detect the location of the rat; TSE Systems software was used to calculate the time spent in each compartment and the motor activity in the whole apparatus.

Procedure. Each experiment consisted of three phases during which each animal was always exposed to the same box: a preconditioning phase (day 1), in which animals were allowed to freely explore the whole box for 15 minutes; a conditioning phase (days 2-9), in which animals were restricted to one of the outer compartments for the odd conditioning sessions and to the other outer compartment for the even sessions; and a testing phase (day 10), in which animals were again allowed to freely explore the whole box for 15 minutes.

As previously described (Cervo et al., 2002, 2005), on the first day, before any drug treatment, each rat was allowed to explore the apparatus for 15 minutes, and the time spent in the three compartments was recorded. Rats were then assigned to treatment groups and conditioning compartments, ensuring that all treatments were matched as closely as possible between compartments. The schedule during the conditioning phase consisted of an intraperitoneal injection of cis-4,4'-DMAR and cocaine or vehicle on alternate days, with a 24-hour interval between conditioning days; this did not influence CPP in our experimental conditions (Cervo et al., 2002, 2005).

On the odd conditioning days, rats were given intraperitoneal cis$4,4^{\prime}$-DMAR or cocaine immediately before being confined to the randomly designated drug side. On the even conditioning days, they were given vehicle and confined to the opposite side. The conditioning session times were 40 minutes and 1 hour, respectively, for cis-4,4'DMAR and cocaine. These schedules were selected on the basis of data in Fig. 4 for 4,4'-DMAR and published data for cocaine (Cervo et al., $2002,2005)$, and they allowed the rats to be exposed at the drugs' peak effect.

This daily order of exposure to the drug under study and vehicle was counterbalanced for the rats in each group. Control animals received vehicle in both compartments.

On the test day, neither drug nor vehicle was injected. Each rat was placed in the middle neutral compartment with free access to the whole apparatus. Over a 15-minute period, we recorded the time spent in each compartment and the motor activity in the whole apparatus.
The difference in time spent in the drug- and vehicle-associated compartments (i.e., preference for the drug-associated side) was taken as a measure of place conditioning.

\section{Results}

\section{cis-4,4' -DMAR Metabolites in Plasma and Brain}

The QSAR Toolbox predicted several potential metabolites in silico entering cis-4,4'-DMAR as a Simplified Molecular Input Line Entry System string: $\mathrm{CC}(\mathrm{N}=\mathrm{C}(\mathrm{N}) \mathrm{O} 1) \mathrm{C} 1 \mathrm{C} 2=$ $\mathrm{CC}=\mathrm{C}(\mathrm{C}) \mathrm{C}=\mathrm{C} 2$.

The full MS scan acquired from plasma and brain samples was searched to locate $m / z$ values for the predicted molecular structures; to filter out interfering signals, plasma and brain samples of untreated rats were acquired the same way and common background peaks were not considered.

Four of the predicted metabolites were detected in both matrices and separated well by the 18-minute gradients, with elution times between 6.0 and 12.0 minutes, as shown by the extracted ion chromatograms (Fig. 1); the retention time of cis4,4'-DMAR was 11.72 minutes.

We confirmed the structures of cis-4,4'-DMAR (Supplemental Fig. 2) and of the metabolites identified, in the plasma and brain, interpreting the MS and MS/MS spectra extracted from each chromatographic peak. We identified metabolite M1 (Supplemental Fig. 3) as due to hydroxylation of the paramethyl group on the aromatic ring or direct hydroxylation of the aromatic ring. We detected other peaks corresponding to the extracted ion chromatogram of M1 $\mathrm{m} / z$ of $207.1128 \pm$ $10 \mathrm{ppm}$ (peaks a, b and c in Fig. 1), probably due to other hydroxylated isomers of cis-4,4'-DMAR; however, no MS/MS spectra were obtained for these peaks because of their low intensities (data not shown). We also identified other metabolites whose MS spectra were consistent with 1) oxidation of the para-methyl group leading to the corresponding carboxylic acid (M2, Supplemental Fig. 4), 2) hydrolysis of the 2-aminooxazoline ring (M3; Supplemental Fig. 5), and 3) oxidative deamination of the 2-amino-oxazoline ring (M4; Supplemental Fig. 6)

Figure 2 shows the proposed in vivo metabolic pathway of cis-4,4'-DMAR, involving phase 1 metabolism reactions.

\section{4,4' -DMAR Absolute Levels and Semiquantitative Analysis of Metabolites}

The plasma PK profile of cis-4,4'-DMAR after a single intraperitoneal injection (Fig. 3A) gave the highest concentration $(241.7 \pm 94.2 \mathrm{ng} / \mathrm{ml})$ at the first sampling time (15 minutes) and had a rapid decline thereafter (no longer detectable 8 hours after the dose), with a $t_{1 / 2}$ of 56.8 minutes (calculated on the last three points). The plasma $\mathrm{AUC}_{0-4 \mathrm{~h}}$ was $0.319 \mu \mathrm{g} / \mathrm{ml}$ per hour. In brain tissues (Fig. 3A), cis-4,4'DMAR reached $C_{\max }(3569 \pm 1195 \mathrm{ng} / \mathrm{g}) 30-60$ minutes after the injection and then declined, with a $t_{1 / 2}$ of 46.5 minutes until 8 hours, when levels were quantifiable only in one rat; $\mathrm{AUC}_{0-8 \mathrm{~h}}$ in brain was $8.532 \mu \mathrm{g} / \mathrm{g}$ per hour. The brain $\mathrm{AUC}_{0-4 \mathrm{~h}} /$ plasma $\mathrm{AUC}_{0-4 \mathrm{~h}}$ ratio was 24 , indicating high penetration in the brain.

Metabolites M1, M3, and M4 had a MS peak area $<10 \%$ of the parent compound in the plasma and brain at each time point (data not shown); M2 had even higher values in plasma than those of cis-4,4'-DMAR (Fig. 3C). Since no reference 
A

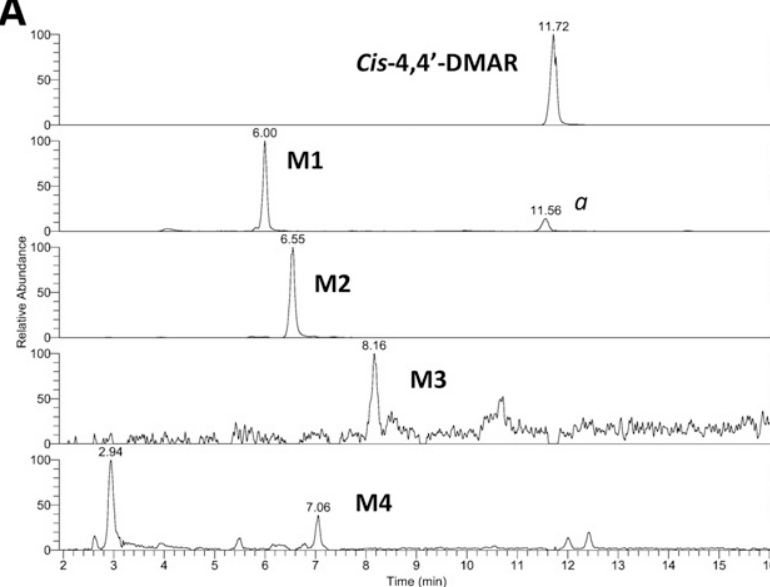

B

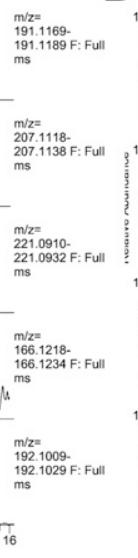

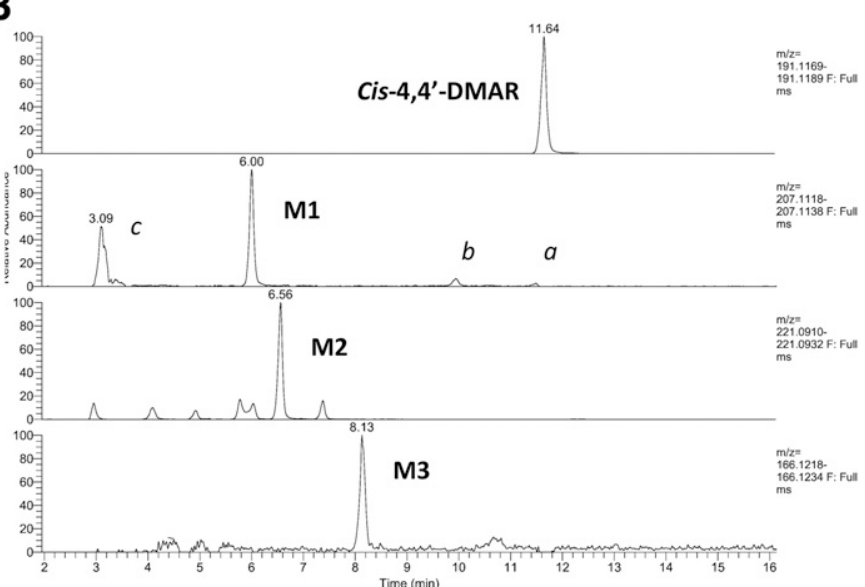

\begin{tabular}{|c|c|c|c|c|c|}
\hline Peak ID & Simulator of metabolism & $\begin{array}{c}\text { Calculated } \mathrm{m} / \mathrm{z} \\
( \pm 10 \mathrm{ppm})\end{array}$ & $\begin{array}{c}\text { Measured } \\
m / z\end{array}$ & Molecular formula & Metabolic reaction \\
\hline 4,4'-DMAR & - & 191.1179 & 191.1178 & $\mathrm{C}_{11} \mathrm{H}_{14} \mathrm{~N}_{2} \mathrm{O}$ & - \\
\hline M1 & Rat liver S9 & 207.1128 & 207.1131 & $\mathrm{C}_{11} \mathrm{H}_{14} \mathrm{~N}_{2} \mathrm{O}_{2}$ & Hyrdoxylation \\
\hline M2 & Rat liver S9 & 221.0921 & 221.0922 & $\mathrm{C}_{11} \mathrm{H}_{12} \mathrm{~N}_{2} \mathrm{O}_{3}$ & Oxidation \\
\hline M3 & Hydrolysis (acidic or basic) & 166.1226 & 166.1229 & $\mathrm{C}_{11} \mathrm{H}_{15} \mathrm{~N}_{2} \mathrm{O}$ & Hydrolysis \\
\hline M4 & Microbial metabolism & 192.1019 & 192.1017 & $\mathrm{C}_{11} \mathrm{H}_{13} \mathrm{~N}_{2} \mathrm{O}$ & Oxidative deamination \\
\hline
\end{tabular}

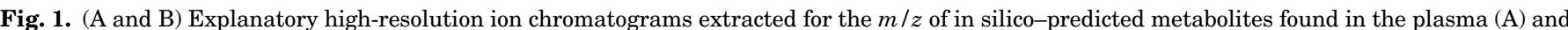

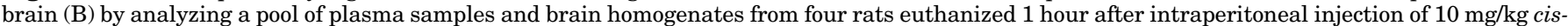

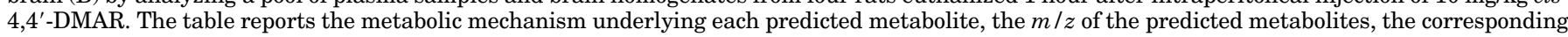
$\mathrm{m} / \mathrm{z}$ measured in biologic tissues after in vivo treatment, the molecular formula, and the proposed metabolic reaction.

standard metabolite M2 was available, we could not determine its absolute plasma and brain levels; therefore, the data are expressed as the ratio of analyte peak areas to IS peak area (response) normalized to milliliters of plasma or grams of tissue.

The PK profile of M2 in plasma (Fig. 3C) had a $t_{\max }$ of 30 minutes, whereas the maximum response in the brain was reached 1 hour after the injection (Fig. 3D); in both matrices,
M2 was detectable up to 8 hours. Plasma and brain levels declined in parallel, with $t_{1 / 2}$ values of 96 minutes and 104 minutes, respectively; M2 had a very low brain-toplasma ratio $\left(\mathrm{AUC}_{0-8 \mathrm{~h} \text { brain }} / \mathrm{AUC}_{0-8 \mathrm{~h} \text { plasma }}=0.05\right)$, indicating weak ability to cross the blood-brain barrier (BBB).

As shown in Table 1 , the concentrations 30 minutes after the 14 th dose were comparable to or slightly lower than 30 minutes after the first dose $(t$ test, $P>0.05)$, indicating no

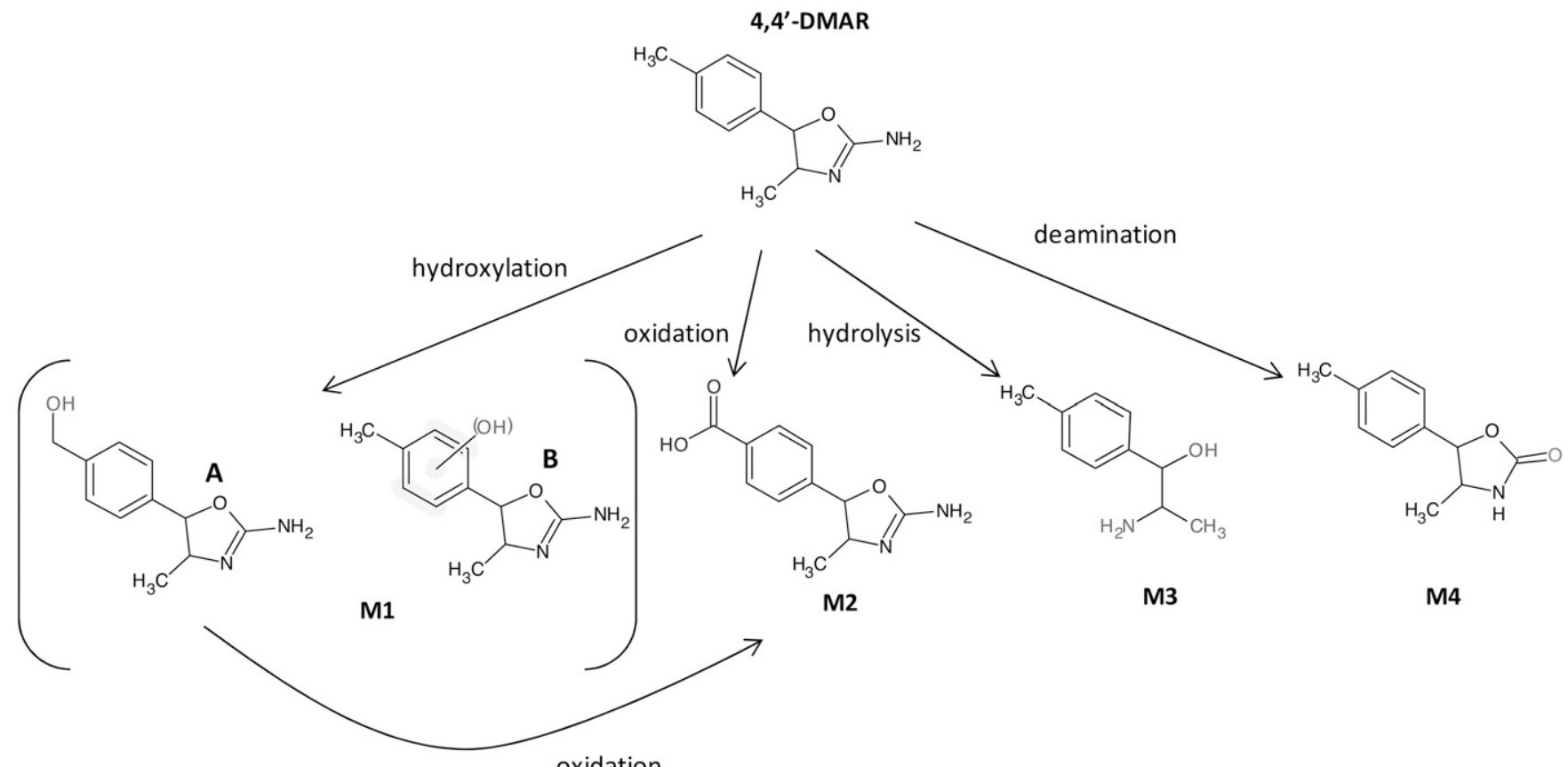

Fig. 2. Proposed in vivo metabolic pathway of cis-4,4'-DMAR with metabolite identification; ambiguous assignments of functional groups are shown as Markush structures. 

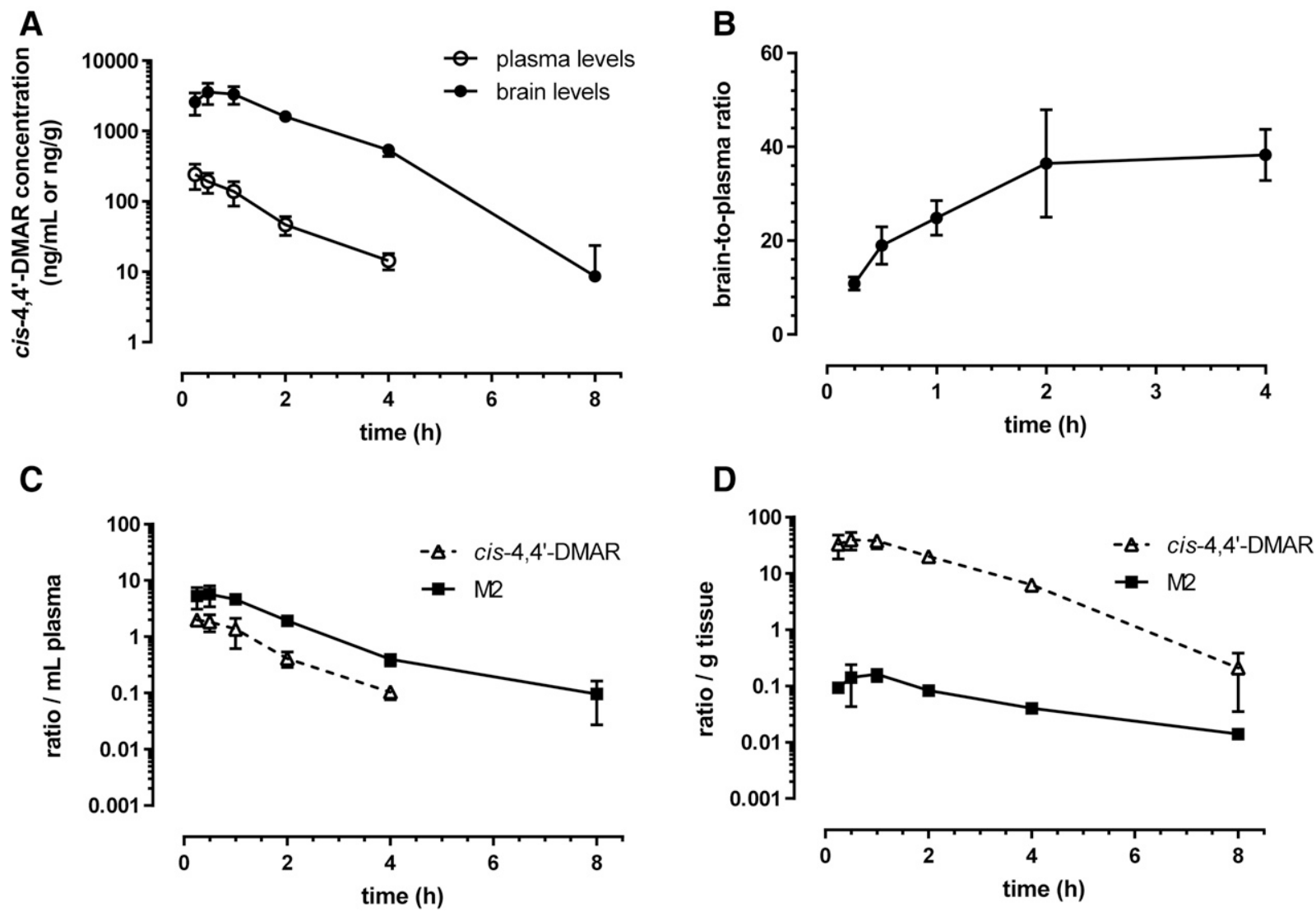

Fig. 3. (A) Time course of cis-4,4'-DMAR concentrations in the plasma (white circles) and brain (black circles) after an $10 \mathrm{mg} / \mathrm{kg}$ intraperitoneal injection. (B) Time course (0-4 hours) of the brain-to-plasma ratio. Each point is the mean \pm S.D. of three to four rats. (C and D) Time course of metabolite M2 in the (C) plasma and (D) brain of rats injected with a single intraperitoneal dose of 4,4'-DMAR $10 \mathrm{mg} / \mathrm{kg}$ and euthanized after $15 \mathrm{minutes}$, 30 minutes, 1 hour, 2 hours, 4 hours, 8 hours, or 24 hours. The monitored ion transitions for M2 were $\mathrm{m} / z 221.1 \rightarrow \mathrm{m} / z 178.1$ (quantifier; collision energy, $10 \mathrm{eV}$ ) and $\mathrm{m} / z 221.1 \rightarrow \mathrm{m} / z$ 117.1 (qualifier; collision energy, $25 \mathrm{eV}$ ). Levels of the metabolite M2 (black squares) are expressed as the peak area ratio of the analyte to the IS, normalized to milliliters of plasma or grams of tissue. Each point is the mean \pm S.D. of three to four animals. For comparison, the ratio of cis-4,4'-DMAR is reported in parallel (white triangles, dotted lines).

accumulation after multiple doses. As expected, 24 hours after the 13th daily dose, cis-4,4'-DMAR was not detectable in either the plasma or brain. With cis-4,4'-DMAR $(10 \mathrm{mg} / \mathrm{kg}$ per day intraperitoneally for 14 days), there was no accumulation of the metabolites (data not shown).

\section{Behavioral Studies}

Spontaneous Locomotor Activity. Figure 4A shows the spontaneous locomotor activity in the 5 hours after a single intraperitoneal injection of 3 or $10 \mathrm{mg} / \mathrm{kg}$ cis-4,4'-DMAR or vehicle. The number of beam breaks was dose-dependently increased by the compound, compared with vehicle. Motor activity had already increased in the first hour post-treatment and remained significant for 2 hours and 4 hours with doses of $3 \mathrm{mg} / \mathrm{kg}$ and $10 \mathrm{mg} / \mathrm{kg}$, respectively.
After the 14th dose, the increase in locomotor activity occurred earlier and was sustained longer (Fig. 4B), although this did not result in statistically different $\mathrm{AUC}_{\text {basal-5h }}$ values (Fig. 4D). Forty-eight hours after the 14th dose, rats were injected again with 3 and $10 \mathrm{mg} / \mathrm{kg}$ cis-4,4'-DMAR and vehicle to check for any rebound effect. There was a further increase in motor activity after this challenge dose, with the corresponding $\mathrm{AUC}_{\mathrm{basal}-5 \mathrm{~h}}$ after $10 \mathrm{mg} / \mathrm{kg}$ significantly higher than after the first and 14th dose (one-way analysis of variance of matched measures, followed by multiple comparisons with the Newman-Keuls post hoc test) (Fig. 4, C and D).

CPP. Figure 5A shows the time rats in the five experimental groups spent in the three compartments during the preconditioning phase; as required, there were no significant differences.

TABLE 1

Plasma and brain concentrations of cis-4,4'-DMAR after intraperitoneal injection of $10 \mathrm{mg} / \mathrm{kg}$ once a day for 14 days

\begin{tabular}{lccc}
\hline & 30 min after First Dose ${ }^{a}$ & 30 min after 14th Dose & 24 h after 13th Dose \\
\hline Plasma (ng/ml) & $241.71 \pm 94.24$ & $161.59 \pm 17.61$ & Not detectable \\
Brain (ng/g) & $3569.09 \pm 1195.01$ & $2363.71 \pm 307.24$ & Not detectable \\
\hline
\end{tabular}

${ }^{a}$ For comparison, the concentrations measured 30 minutes after a single dose (from Fig. 3 ) are shown. 
A

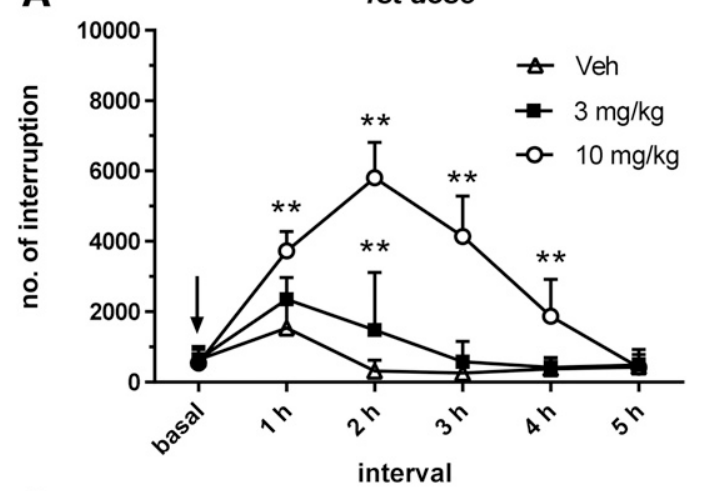

C

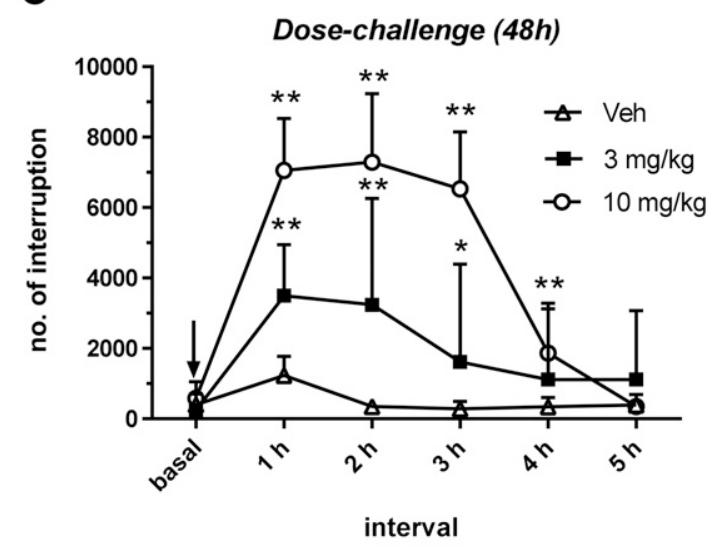

B
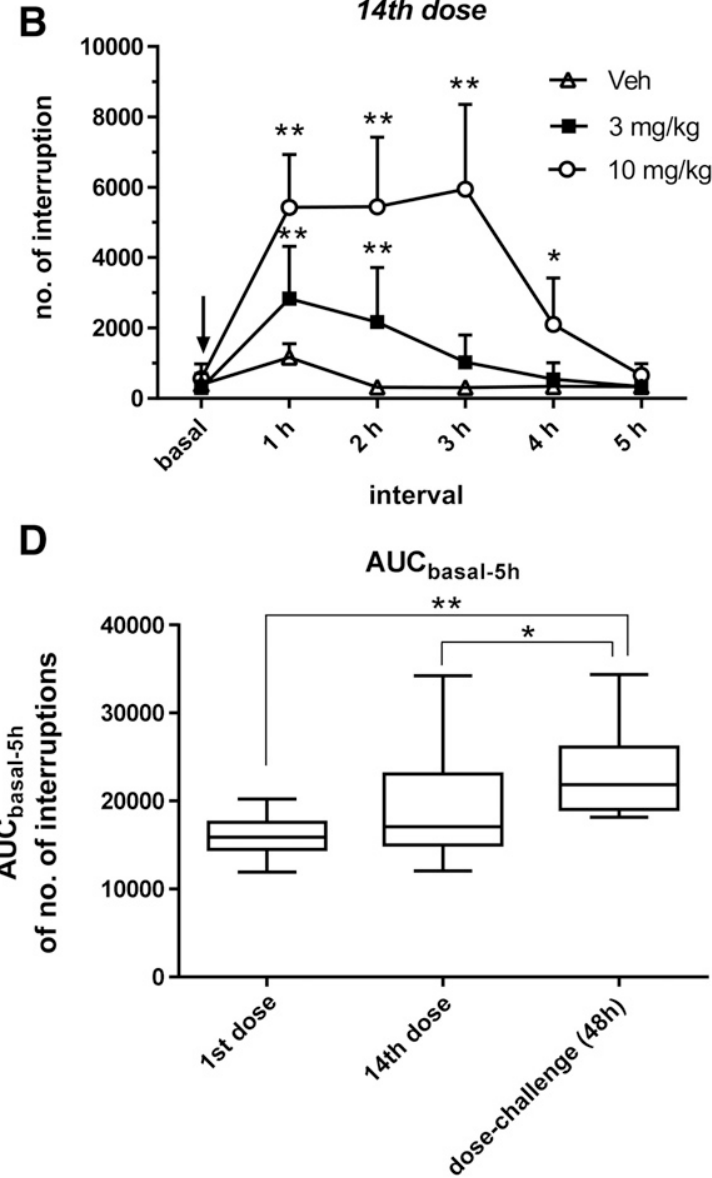

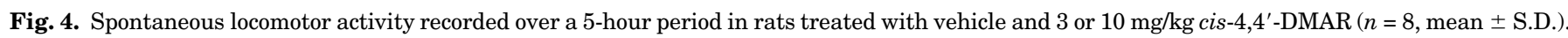

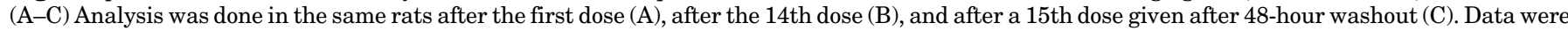

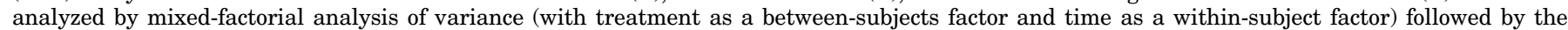

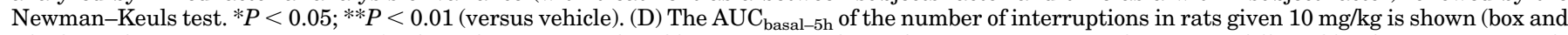

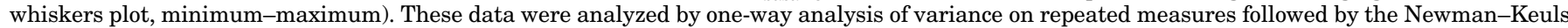
post hoc test. Significant comparisons are indicated. $* P<0.05 ; * * P<0.01$.

Figure 5B shows the effects of eight conditioning sessions with vehicle, cis-4,4'-DMAR (1, 3, and $10 \mathrm{mg} / \mathrm{kg}$, i.p.), and cocaine $(10 \mathrm{mg} / \mathrm{kg}$, i.p.) on the time spent in the conditioned drug-associated side. One-way analysis of variance followed by post hoc comparisons showed that $10 \mathrm{mg} / \mathrm{kg}$ cis-4,4'DMAR (but not 1 and $3 \mathrm{mg} / \mathrm{kg}$ ) and $10 \mathrm{mg} / \mathrm{kg}$ cocaine induced a clear CPP $(P<0.05$ versus vehicle group, Newman-Keuls test).

\section{Discussion}

The main aim of this study was to investigate the behavioral effects of the psychoactive substance cis-4,4'-DMAR and to correlate them with its brain disposition in rats after single and repeated doses $(10 \mathrm{mg} / \mathrm{kg}$, i.p.); to our knowledge, this is the first study to investigate the in vivo metabolism of this drug.

The PK profile of cis-4,4'-DMAR in plasma after intraperitoneal injection confirmed previous data (Lucchetti et al., 2016), with very rapid absorption, a $C_{\max }$ within 15 minutes, and a rapid decline in plasma drug concentration, undetectable after 4 hours; an elimination half-time of about 5 hours was previously determined after intravenous injection (Lucchetti et al., 2016).cis-4,4'-DMAR distributed to the brain rapidly and extensively after intraperitoneal injection, with a $t_{\max }$ of 30-60 minutes and a brain-toplasma ratio of 24 , consistent with the lipophilicity $(\log \mathrm{P}=$ 1.5) of this small molecule. This brain-to-plasma ratio is three times that reported for the precursor cis-4-MAR (approximately 7 after i.p. injection) (Meririnne et al., 2004). A half-time of 46.5 minutes was estimated using the last three points until 8 hours, similar to that for the cis4-MAR analog (Bunker et al., 1990; Kankaanpää et al., 2001, 2002; Meririnne et al., 2004).

Regarding the in vivo metabolism of cis-4,4'-DMAR, we identified metabolites due to hydroxylation (M1), hydrolysis (M3), and oxidative deamination (M4) (i.e., metabolic reactions already described for the precursor 4-MAR) (Henderson et al., 1995). The metabolite originating from hydrolysis is the para-methyl derivative of norephedrine, a psychoactive drug that is used as a stimulant, decongestant, and anorectic agent (Flavahan, 2005), suggesting that the M3 metabolite might have similar activities. Furthermore, both oxidations and aromatic hydroxylation are metabolic pathways typical of amphetamine-like compounds (Alleva, 1963; Dring et al., 1966; Ellison et al., 1966; Theobald and Maurer, 2007; Rohanova and Balikova, 2009; Maurer, 2010; Welter et al., 2014). However, the main metabolite found in both the plasma 

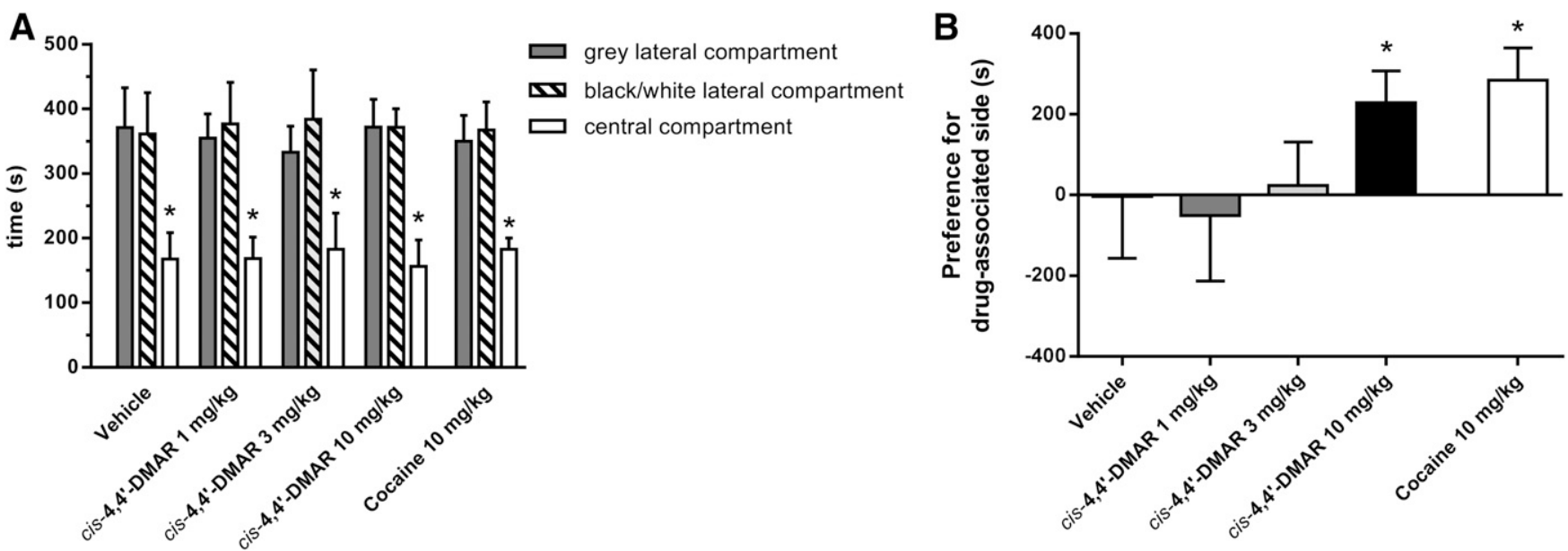

Fig. 5. cis-4,4'-DMAR-induced CPP. (A) During the preconditioning phase, rats had no treatment and the groups indicated refer just to the planned treatments. The mean time \pm S.D. $(n=8)$ spent by rats in the three compartments of the CPP cage is shown. Data were analyzed by two-way ANOVA followed by the Newman-Keuls test. $* P<0.05$ (versus gray and black/white compartment). (B) Data obtained on the test day, after the conditioning phase. The mean time \pm S.D. $(n=8)$ in the cis-4,4'-DMAR or cocaine-paired side is shown, corrected for the time spent in the vehicle-paired side. Data were analyzed by one-way ANOVA followed by the Newman-Keuls post hoc test. $* P<0.05$ (versus the vehicle-treated group).

and brain (M2) was due to oxidation of the para-methyl group of cis-4,4'-DMAR, a metabolic reaction not observed for 4-MAR. Although absolute quantification of this metabolite is not possible because of the lack of a reference standard, comparison of the MS signal intensities showed that M2 already had higher plasma levels than the parent compound at 15 minutes and at all of the time points thereafter; this metabolite reached $C_{\max }$ after 30 minutes and could be detected until 8 hours (i.e., longer than the parent compound). The higher plasma levels of M2 than the parent compound might be useful for a more sensitive assessment of cis-4,4' DMAR intake in humans. However, the BBB passage of M2 was very low (brain-to-plasma ratio $=0.05$ ) and resulted in brain concentrations 500 times lower than the parent compound, suggesting that M2 does not contribute to the pharmacological central effects of cis-4,4'-DMAR.

A single intraperitoneal injection of $3-10 \mathrm{mg} / \mathrm{kg}$ cis $-4,4^{\prime}$ DMAR increased spontaneous locomotor activity in a dosedependent manner. This effect resembled those previously observed with amphetamine and its analogs, such as phenethylamines/3,4-methylenedioxymethamphetamine-like drugs (Wellman et al., 2009; Páleníček et al., 2011; López-Arnau et al., 2012; Aarde et al., 2013; Miliano et al., 2016), and is very likely attributable to the fact that cis-4, $4^{\prime}$ DMAR induces the release of biologic monoamines, particularly dopamine (Charntikov et al., 2011; Brandt et al., 2014; McLaughlin et al., 2015). The rapid appearance and rapid decline of this behavioral effect is consistent with the PK profile of the compound in the brain, although a delay of about 1 hour could be noted (Supplemental Fig. 7). Several reasons could explain this delay (Louizos et al., 2014), such as the time needed for receptor-activated signal transduction, a rapid sensitization of receptors, or formation of metabolites with agonist activity. The latter possibility is unlikely, considering the low BBB passage and the brain PK profile of the main metabolite (M2). With regard to the second possibility, it has been reported that an immediate and long-lasting dopaminergic sensitization is already elicited after a single injection of amphetamine and other psychostimulants (Vanderschuren et al., 1999; Chinen et al., 2006; Kameda et al., 2011; Marinho et al., 2015). Consistently, after repeated treatment (once a day for 14 days), the compound's ability to stimulate locomotor activity occurred earlier and it was sustained longer compared with that measured after the first dose, with a significant increase with a new drug challenge after 48-hour washout. Since no drug accumulation or increase in drug bioavailability was observed after repeated injections, pharmacodynamics adaptation mechanisms probably underlie these observations. The behavioral sensitization and hyperresponsiveness of dopaminergic neurons has already been described after repeated administration of methamphetamine, as well as with other phenethylamine derivatives (Nishikawa et al., 1983; Fukushima et al., 2007; Miliano et al., 2016).

We also describe for the first time, to our knowledge, the rewarding effect of cis-4, $4^{\prime}$-DMAR evaluated in the CPP test, an established method for studying the motivational properties of a substances of abuse (Mucha et al., 1982; Tzschentke and Schmidt, 1998; Tzschentke, 2007). In the CPP paradigm the neutral environmental stimuli (i.e. different compartments) not capable to induce conditioned response, after repeatedly pairing with the primary motivational properties of the drug (i.e. unconditioned stimuli) during the conditioning phase, are prone to acquire secondary motivational effects able to evoke a response (i.e. conditioned stimuli) (Mucha et al., 1982; Tzschentke and Schmidt, 1998; Tzschentke, 2007). Specifically, after $10 \mathrm{mg} / \mathrm{kg}$ cis-4,4'-DMAR, rats showed a preference for the side associated with the drug and this effect resembled that seen with $10 \mathrm{mg} / \mathrm{kg}$ cocaine. These data clearly indicate that $c i s-4,4^{\prime}$-DMAR has positive motivational properties, suggesting a high risk of addiction in humans.

These data highlight the importance of studying psychoactive substances with an approach combining PK and behavioral investigations in animal models. In particular, the analysis of brain disposition and the drug's metabolites is vital to better understand the time course of the behavioral effects and to predict the consequences of repeated doses. 


\section{Authorship Contributions}

Participated in research design: Lucchetti, Marzo, Di Clemente, Gobbi, Cervo.

Conducted experiments: Lucchetti, Marzo, Di Clemente, Moro.

Performed data analysis: Lucchetti, Marzo, Passoni, Bagnati,

Gobbi, Cervo.

Wrote or contributed to the writing of the manuscript: Lucchetti, Gobbi, Cervo.

\section{References}

Aarde SM, Huang PK, Creehan KM, Dickerson TJ, and Taffe MA (2013) The novel recreational drug 3,4-methylenedioxypyrovalerone (MDPV) is a potent psychomotor stimulant: self-administration and locomotor activity in rats. Neuropharmacology 71:130-140.

Alleva JJ (1963) Metabolism of tranyleypromine-C14 and Dl amphetamine-C14 in the rat. J Med Chem 6:621-624.

Brandt SD, Baumann MH, Partilla JS, Kavanagh PV, Power JD, Talbot B, Twamley B, Mahony O, O'Brien J, Elliott SP, et al. (2014) Characterization of a novel and potentially lethal designer drug ( \pm )-cis-para-methyl-4-methylaminorex $\left(4,4^{\prime}\right.$ DMAR, or 'Serotoni'). Drug Test Anal 6:684-695.

Bunker CF, Johnson M, Gibb JW, Bush LG, and Hanson GR (1990) Neurochemical effects of an acute treatment with 4-methylaminorex: a new stimulant of abuse. Eur J Pharmacol 180:103-111.

Cervo L, Burbassi S, Colovic M, and Caccia S (2005) Selective antagonist at D3 receptors, but not non-selective partial agonists, influences the expression of cocaine-induced conditioned place preference in free-feeding rats. Pharmacol Biochem Behav 82:727-734

Cervo L, Rozio M, Ekalle-Soppo CB, Carnovali F, Santangelo E, and Samanin R (2002) Stimulation of serotonin1B receptors induces conditioned place aversion and facilitates cocaine place conditioning in rats. Psychopharmacology (Berl) 163:142-150.

Charntikov S, Der-Ghazarian T, Herbert MS, Horn LR, Widarma CB, Gutierrez A Varela FA, and McDougall SA (2011) Importance of D1 and D2 receptors in the dorsal caudate-putamen for the locomotor activity and stereotyped behaviors of preweanling rats. Neuroscience 183:121-133.

Chinen CC, Faria RR, and Frussa-Filho R (2006) Characterization of the rapid-onset type of behavioral sensitization to amphetamine in mice: role of drug-environment conditioning. Neuropsychopharmacology 31:151-159.

Cosbey S, Kirk S, McNaul M, Peters L, Prentice B, Quinn A, Elliott SP, Brandt SD, and Archer RP (2014) Multiple fatalities involving a new designer drug: paramethyl-4-methylaminorex. I Anal Toxicol 38:383-384.

Costa E, Naimzada KM, and Revuelta A (1971) Effect of phenmetrazine, aminorex and ( ) p-chloramphetamine on the motor activity and turnover rate of brain catecholamines. $\mathrm{Br}$ J Pharmacol 43:570-579.

Davis FT and Brewster ME (1988) A fatality involving U4Euh, a cyclic derivative of phenylpropanolamine. J Forensic Sci 33:549-553.

Dolezal T and Krsiak M (2002) Guaifenesin enhances the analgesic potency of paracetamol in mice. Naunyn Schmiedebergs Arch Pharmacol 366:551-554

Dring LG, Smith RL, and Williams RT (1966) The fate of amphetamine in man and other mammals. $J$ Pharm Pharmacol 18:402-404.

Ellison T, Gutzait L, and Van Loon EJ (1966) The comparative metabolism of d-amphetamine-C14 in the rat, dog and monkey. J Pharmacol Exp Ther 152:383-387.

Flavahan NA (2005) Phenylpropanolamine constricts mouse and human blood vessels by preferentially activating alpha2-adrenoceptors. J Pharmacol Exp Ther 313: $432-439$.

Fukushima S, Shen H, Hata H, Ohara A, Ohmi K, Ikeda K, Numachi Y, Kobayashi H, Hall FS, Uhl GR, et al. (2007) Methamphetamine-induced locomotor activity and sensitization in dopamine transporter and vesicular monoamine transporter 2 double mutant mice. Psychopharmacology (Berl) 193:55-62.

Glanville J, Dargan PI, and Wood DM (2015) 4-methyl-5-(4-methylphenyl)-4,5dihydrooxazol-2-amine (4,4'-DMAR, 4,4'-dimethylaminorex): availability, prevalence of use, desired effects and acute toxicity. Hum Psychopharmacol 30:193-198.

Henderson GL, Harkey MR, and Chueh YT (1995) Metabolism of 4-methylaminorex ("EU4EA") in the rat. J Anal Toxicol 19:563-570.

Hofmaier T, Luf A, Seddik A, Stockner T, Holy M, Freissmuth M, Ecker GF, Schmid $\mathrm{R}$, Sitte HH, and Kudlacek O (2014) Aminorex, a metabolite of the cocaine adulterant levamisole, exerts amphetamine like actions at monoamine transporters. Neurochem Int 73:32-41.

Kameda SR, Fukushiro DF, Trombin TF, Procópio-Souza R, Patti CL, Hollais AW, Calzavara MB, Abílio VC, Ribeiro RA, Tufik S, et al. (2011) Adolescent mice are more vulnerable than adults to single injection-induced behavioral sensitization to amphetamine. Pharmacol Biochem Behav 98:320-324.

Kankaanpää A, Ellermaa S, Meririnne E, Hirsjärvi P, and Seppälä T (2002) Acute neurochemical and behavioral effects of stereoisomers of 4-methylaminorex in relation to brain drug concentrations. J Pharmacol Exp Ther 300:450-459.
Kankaanpää A, Meririnne E, Ellermaa S, Ariniemi K, and Seppälä T (2001) Detection and assay of cis- and trans-isomers of 4-methylaminorex in urine, plasma and tissue samples. Forensic Sci Int 121:57-64.

Kay JM, Smith P, and Heath D (1971) Aminorex and the pulmonary circulation. Thorax 26:262-270.

López-Arnau R, Martínez-Clemente J, Pubill D, Escubedo E, and Camarasa J (2012) Comparative neuropharmacology of three psychostimulant cathinone derivatives: butylone, mephedrone and methylone. Br J Pharmacol 167:407-420.

Louizos C, Yáñez JA, Forrest ML, and Davies NM (2014) Understanding the hysteresis loop conundrum in pharmacokinetic/pharmacodynamic relationships. $J$ Pharm Pharm Sci 17:34-91.

Lucchetti J, Marzo CM, Di Clemente A, Cervo L, and Gobbi M (2016) A validated, sensitive HPLC-MS/MS method for quantification of cis-para-methyl-4-methylaminorex (cis-4,4'-DMAR) in rat and human plasma: application to pharmacokinetic studies in rats. Drug Test Anal DOI: [published ahead of print].

Marinho EA, Oliveira-Lima AJ, Santos R, Hollais AW, Baldaia MA, Wuo-Silva R, Yokoyama TS, Takatsu-Coleman AL, Patti CL, Longo BM, et al. (2015) Effects of rimonabant on the development of single dose-induced behavioral sensitization to ethanol, morphine and cocaine in mice. Prog Neuropsychopharmacol Biol Psychiatry 58:22-31.

Maurer HH (2010) Chemistry, pharmacology, and metabolism of emerging drugs of abuse. Ther Drug Monit 32:544-549.

McLaughlin G, Morris N, Kavanagh PV, Power JD, Twamley B, O'Brien J, Talbot B, Dowling G, Mahony O, Brandt SD, et al. (2015) Synthesis, characterization, and monoamine transporter activity of the new psychoactive substance $3^{\prime}, 4^{\prime}$ methylenedioxy-4-methylaminorex (MDMAR). Drug Test Anal 7:555-564.

Meririnne E, Ellermaa S, Kankaanpää A, Bardy A, and Seppälä T (2004) Pharmacokinetics and tissue distribution of the stereoisomers of 4-methylaminorex in the rat. J Pharmacol Exp Ther 309:1198-1205.

Miliano C, Serpelloni G, Rimondo C, Mereu M, Marti M, and De Luca MA (2016) Neuropharmacology of new psychoactive substances (NPS): focus on the rewarding and reinforcing properties of cannabimimetics and amphetamine-like stimulants. Front Neurosci 10:153.

Mucha RF, van der Kooy D, O'Shaughnessy M, and Bucenieks P (1982) Drug reinforcement studied by the use of place conditioning in rat. Brain Res 243:91-105.

Nishikawa T, Mataga N, Takashima M, and Toru M (1983) Behavioral sensitization and relative hyperresponsiveness of striatal and limbic dopaminergic neurons after repeated methamphetamine treatment. Eur J Pharmacol 88:195-203.

Páleníček T, Balíková M, Rohanová M, Novák T, Horáček J, Fujáková M, and Höschl C (2011) Behavioral, hyperthermic and pharmacokinetic profile of para-methoxymethamphetamine (PMMA) in rats. Pharmacol Biochem Behav 98 130-139.

Poos GI, Carson JR, Rosenau JD, Roszkowski AP, Kelley NM, and McGowin J (1963) 2-amino-5-aryl-2-oxazolines. Potent new anorectic agents. J Med Chem 6:266-272

Rohanova M and Balikova M (2009) Studies on distribution and metabolism of paramethoxymethamphetamine (PMMA) in rats after subcutaneous administration. Toxicology 259:61-68.

Theobald DS and Maurer HH (2007) Identification of monoamine oxidase and cytochrome P450 isoenzymes involved in the deamination of phenethylamine-derived designer drugs (2C-series). Biochem Pharmacol 73:287-297.

Tzschentke TM (2007) Measuring reward with the conditioned place preference (CPP) paradigm: update of the last decade. Addict Biol 12:227-462.

Tzschentke TM and Schmidt WJ (1998) Discrete quinolinic acid lesions of the rat prelimbic medial prefrontal cortex affect cocaine- and MK-801-, but not morphineand amphetamine-induced reward and psychomotor activation as measured with the place preference conditioning paradigm. Behav Brain Res 97:115-127.

Vanderschuren LJ, Schmidt ED, De Vries TJ, Van Moorsel CA, Tilders FJ, and Schoffelmeer AN (1999) A single exposure to amphetamine is sufficient to induce long-term behavioral, neuroendocrine, and neurochemical sensitization in rats. J Neurosci 19:9579-9586.

Wellman PJ, Davis KW, Clifford PS, Rothman RB, and Blough BE (2009) Changes in feeding and locomotion induced by amphetamine analogs in rats. Drug Alcohol Depend 100:234-239.

Welter J, Meyer MR, Kavanagh P, and Maurer HH (2014) Studies on the metabolism and the detectability of 4-methyl-amphetamine and its isomers 2-methyl-amphetamine and 3-methyl-amphetamine in rat urine using GC-MS and LC-(high-resolution)-MSn Anal Bioanal Chem 406:1957-1974.

Zhang Y, Huo M, Zhou J, and Xie S (2010) PKSolver: an add-in program for pharmacokinetic and pharmacodynamic data analysis in Microsoft Excel. Comput Methods Programs Biomed 99:306-314.

Address correspondence to: Jacopo Lucchetti, Laboratory of Pharmacodynamic and Pharmacokinetics, Department of Molecular Biochemistry and Pharmacology, IRCCS-Istituto di Ricerche Farmacologiche Mario Negri, via La Masa 19, 20156 Milan, Italy. E-mail: jacopo.lucchetti@marionegri.it 